\title{
Algal 'lagoon' effect for oxygenating MFC cathodes
}

\author{
Iwona Gajda $^{\mathrm{a}}$, Andrew Stinchcombe ${ }^{\mathrm{a}}$, John Greenman ${ }^{\mathrm{a}, \mathrm{b}}$, Chris Melhuish ${ }^{\mathrm{a}}$, $\underline{\text { Ioannis }}$ \\ Ieropoulos $^{\mathrm{a}, \mathrm{b}^{*}}$ \\ ${ }^{a}$ Bristol Robotics Laboratory, Block T, UWE, Bristol, Coldharbour Lane, Bristol BS16 1QY, \\ $U K$ \\ ${ }^{b}$ School of Life Sciences, UWE, Bristol, Coldharbour Lane, Bristol BS16 1QY,UK \\ *ioannis.ieropoulos@brl.ac.uk
}

\begin{abstract}
This paper describes the active oxygenation performed by photosynthetic organisms in the cathode of a two-chamber Microbial Fuel Cell system. The algal biomass supplied dissolved oxygen to the cathodic oxygen reduction reaction (ORR) in a sustainable manner through the recirculation of the catholyte connected to separate photoreactors, which acted as lagoons. Aiming towards self-sustainable applications, it has been demonstrated that catholyte recirculation could be facilitated by the MFC stack itself when a dc impeller pump was periodically powered by the electricity generated from these same MFCs.
\end{abstract}

Keywords: Lagoon effect, Microbial fuel cells, Photosynthetic cathode, Biomass recovery

\section{Introduction}

As the cost of energy rises, many wastewater facilities are searching for more energy efficient processes. In their effort to become energetically self-sufficient, these technologies are also looking into cost effective and renewable energy sources. The advantages of biofuels are thus numerous, however the debate between food versus fuel and the impact of emissions from burning biodiesel, pushes the search for alternative and truly clean sources of energy. One of many possible solutions lies with non-combustion methods such as fuel cells. The Microbial Fuel Cell is one such solution with the added benefit of cleaner waste, which is the source of 
directly produced current [1] and in addition, it might be used as the power source for sensors [2] robots [3] and mobile phones [4].

To successfully implement the Microbial Fuel Cell (MFC) technology as a viable power source for practical applications on a large scale, power output, cost and operational sustainability, still require further improvement. This would exclude the employment of noble metals (e.g. platinum) and chemicals (e.g. ferricyanide) as catalysts/reagents. Improvement of the cathode oxygen reduction requires oxygen to be constantly supplied to the cathode electrode. One of the most promising attempts improving the sustainability of the system is the integration of photosynthesis into the MFC [5], recognising that illumination - and as a consequence - the level of dissolved oxygen, can effect polarity reversal [6]. Previous photo biocathode investigations showed that photosynthetic organisms can be used as active oxygenators in situ as a monoculture of Chlorella vulgaris [7], mixed culture cultivated on growth media [8] or mixed culture from natural sources cultivated in water [9]. Aiming towards practical applications, the use of mixed, wild algal cultures in the cathode chamber is more viable in comparison to monoculture, which requires aseptic conditions, $\mathrm{pH}$ control and continuous supply of media. However, using active oxygenators such as photosynthetic organisms in situ to perform this task has the unavoidable downside of oxygen depletion during the dark phase, where photosynthesis stops and respiration occurs [6-9]. A photoreactor connected to the cathodic side of MFCs can theoretically produce biomass and also provide oxygenation for the cathodic chamber [10]. Essentially, a photoreactor functions as an algal lagoon first described by Oswald in 1953 [11] and it has been widely used in the wastewater treatment process where the natural photosynthesis is providing oxygenation for the treatment instead of costly mechanical aeration. Nowadays, the lagooning effect is also used extensively in the wastewater treatment in the facultative ponds. Similar to this 
lagooning process, the photoreactors, in this present study, become reservoir tanks providing aeration for the cathode chamber.

Microalgae are promising photosynthetic organisms in comparison to conventional biofuel crops due to their high growth rates, high $\mathrm{CO}_{2}$ fixation and lack of requirement for valuable fertile land. Moreover, their life cycle may support the wastewater treatment process $[12,13]$. It has already been demonstrated that a photo biocathode can fix carbon dioxide into new biomass, whilst at the same time allowing generation of electricity from biodegradable matter $[9,10]$. In MFCs, the electroactive bacteria biodegrade organic matter in the anode, and resultant cations as well as the protons diffuse through the cation selective membrane into the cathode $[14,15]$ where they can be further assimilated by algal growth and locked into new biomass [16] showing energy recovery.

The current study presents the sustainable oxygenation of the MFC cathode by photosynthesis in a 'lagoon' manner and in addition demonstrates that the generated electricity by the stacked MFCs can be used to power a peripheral dc pump as an exemplar practical application. The produced algal biomass could furthermore be utilised as a carbon energy source in the same MFC anodes $[17,18]$ - a direction that will be pursued as part of this study, in an attempt to develop a fully self-sustainable system.

\section{Materials and Methods}

\subsection{MFC design}

A total of 15 MFCs were employed using $25 \mathrm{~mL}$ anode chambers and $25 \mathrm{~mL}$ cathode chambers, separated by a cation exchange membrane (VWR International) as previously described [9]. Anode and cathode electrodes were made of a $270 \mathrm{~cm}^{2}$ sheet of carbon fibre veil $\left(20 \mathrm{~g} / \mathrm{m}^{2}\right)$ (PRF Composite Materials, Poole, UK); these were folded down to approx. $17 \mathrm{~cm}^{3}$ and pierced with a nickel-chrome wire (thickness- $0.45 \mathrm{~mm}$ ) for connecting to the external 
circuit. Further modification of cathode electrodes resulted in 5 different experimental groups (Table 1) that were employed to support algal biofilm development and current collection. Each experimental condition was tested in triplicate. No growth media, $\mathrm{pH}$ control or chemical pre-treatment was used during the MFC operation.

Table 1. Types of electrodes in the cathode biotic and abiotic environment.

\begin{tabular}{|c|c|c|c|}
\hline $\begin{array}{c}\text { MFC } \\
\text { type }\end{array}$ & Electrode & Catholyte & Cathode \\
\hline Water & Carbon veil (Control) & tap water & $\begin{array}{c}\text { (Initially) Abiotic - } \\
\text { (subsequently) turned biotic }\end{array}$ \\
\hline Algae & Carbon veil & tap water & Biotic \\
\hline $\begin{array}{c}\text { Algae } \\
\text { string }\end{array}$ & Carbon veil wrapped with cotton string & tap water & Biotic \\
\hline $\begin{array}{c}\text { Algae } \\
\text { cellulose }\end{array}$ & Carbon veil with cellulose coating & tap water & Biotic \\
\hline $\begin{array}{c}\text { Algae } \\
\text { wire }\end{array}$ & $\begin{array}{c}\text { Carbon veil wrapped with stainless steel } \\
\text { wire }\end{array}$ & tap water & Biotic \\
\hline
\end{tabular}

\subsection{Inoculation and MFC operation}

Activated anaerobic sludge provided by the Wessex Water Scientific Laboratory (Saltford, UK) was used as the inoculum for the MFC anodes. Sludge was mixed with $0.1 \mathrm{M}$ acetate prior to use (pH 7.2) and used thereon for periodic feeding. Pond water (Frenchay, Bristol) was cultivated in a well-illuminated laboratory environment for 2 months prior to the start of experiments, to allow algal growth and development. When it was colonised predominantly by photosynthetic organisms (visibly green), it was used as the inoculum for the cathode halfcell. For the first 40 days MFCs were operated in batch mode to ensure biofilm establishment and electrode colonisation. Subsequently, each of the cathode chambers was connected to the 0.5LSchott photoreactor bottles in which, again algae were re-suspended in fresh pond water (Figure 1). Sterilised deionised water was used as the catholyte in the control MFCs. Anodes were operated in fed-batch mode, periodically supplied with fresh sludge mixed with $0.1 \mathrm{M}$ acetate as the carbon-energy source. Silicone tubing was used to connect the photoreactor bottles to the 16-channel peristaltic pump (205U, Watson Marlow, Falmouth, UK), which was 
feeding into the inflow tubes of the MFCs and which in turn were connected back to the photoreactors, as shown in Fig 5. Marprene tubing was used within the pump manifold and catholyte flow was maintained at a rate of $123 \mathrm{~mL} / \mathrm{h}$. MFCs connected to the photoreactor bottles were operated in a thermostatic light incubator (LMS Ltd., Kent, UK), at $22^{\circ} \mathrm{C}$, which was fitted with Cool White Daylight Tubes (3500 lux per tube). The illumination cycle was set at $14 \mathrm{~h}$ light $/ 10 \mathrm{~h}$ dark. MFCs were operated under $8.2 \mathrm{k} \Omega$ external resistive loads until reaching maturity. During long-term MFC operation, the control (abiotic) cathodes became serendipitously biotic, growing photosynthetic organisms in the chambers as reported earlier [9].

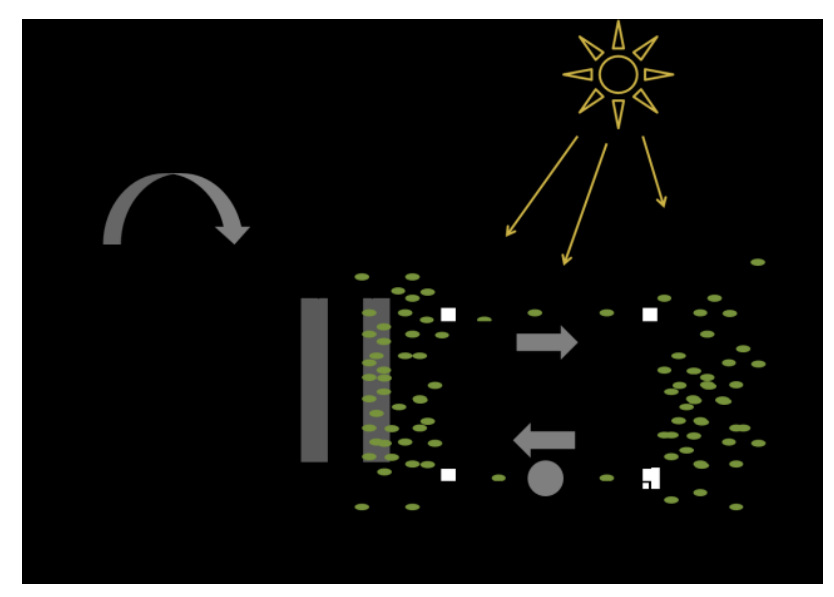

Figure 1.Experimental set-up; two-chamber Microbial Fuel Cell with a biotic cathode connected to the photoreactor.

\subsection{Data Capture and Practical implementation}

MFC output was recorded in volts (V) against time, using an ADC-16 data logger computer interface (Pico Technology Ltd., Cambridgeshire, UK). Practical implementation of all MFCs connected together was demonstrated by charging a 5F super-capacitor (RS, UK) and powering a dc impeller pump (TCS Pumps, M200-S, 3V, RS, UK).

\section{Results}

3.1. Catholyte recirculation during day/night conditions 
Figure 2 presents the open circuit voltage (OCV) of algal-based cathode MFCs. At first, the recirculation of the catholyte was switched OFF (batch mode) and the voltage level was reaching values higher than $500 \mathrm{mV}$ during the light phase, but decreased to $150 \mathrm{mV}$ during the dark period. When the pump was switched ON (black arrow) the difference between the open circuit voltage of the two phases (light and dark) decreased, suggesting that the algal growth in the photo-reactors compensated for the lack of oxygen generation in the smaller cathodic chambers (during the dark period); this is a form of hysteresis, which improved both stability and performance of the MFCs.

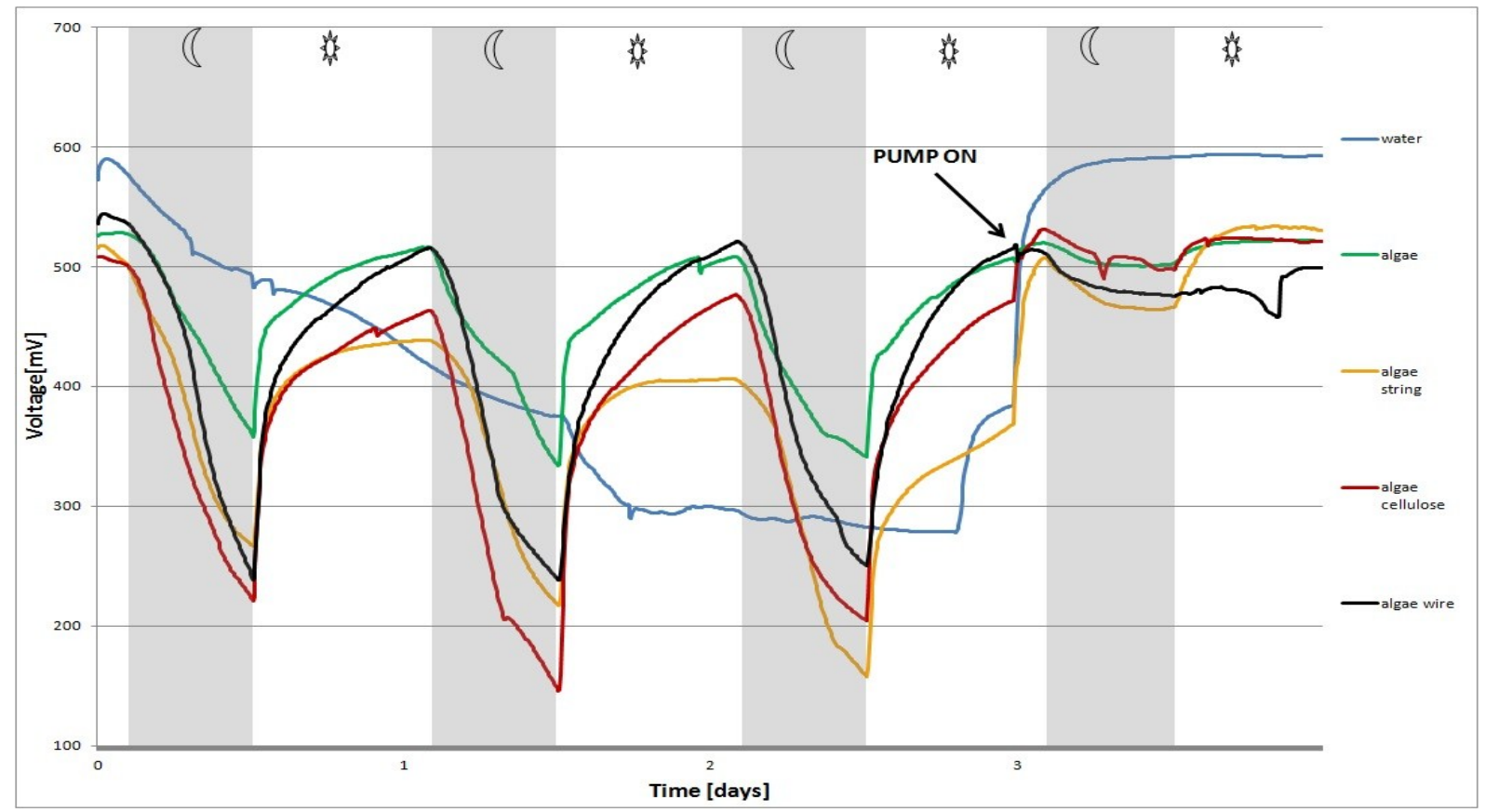

Figure 2. Open circuit voltage (OCV) values of photosynthetic cathode MFCs. 14h day/10night cycle.

In Figure 3 pumping was turned OFF once again, whilst the dark period was increased to $20 \mathrm{~h}$ night over $4 \mathrm{~h}$ day intervals. The voltage value of the MFCs dropped into negative values and the short period of illumination was insufficient for the MFCs to fully recover. When the recirculation pump was switched $\mathrm{ON}$, once again steady open circuit voltage levels were recorded, with a lesser degree of fluctuation between the day/night cycles. 


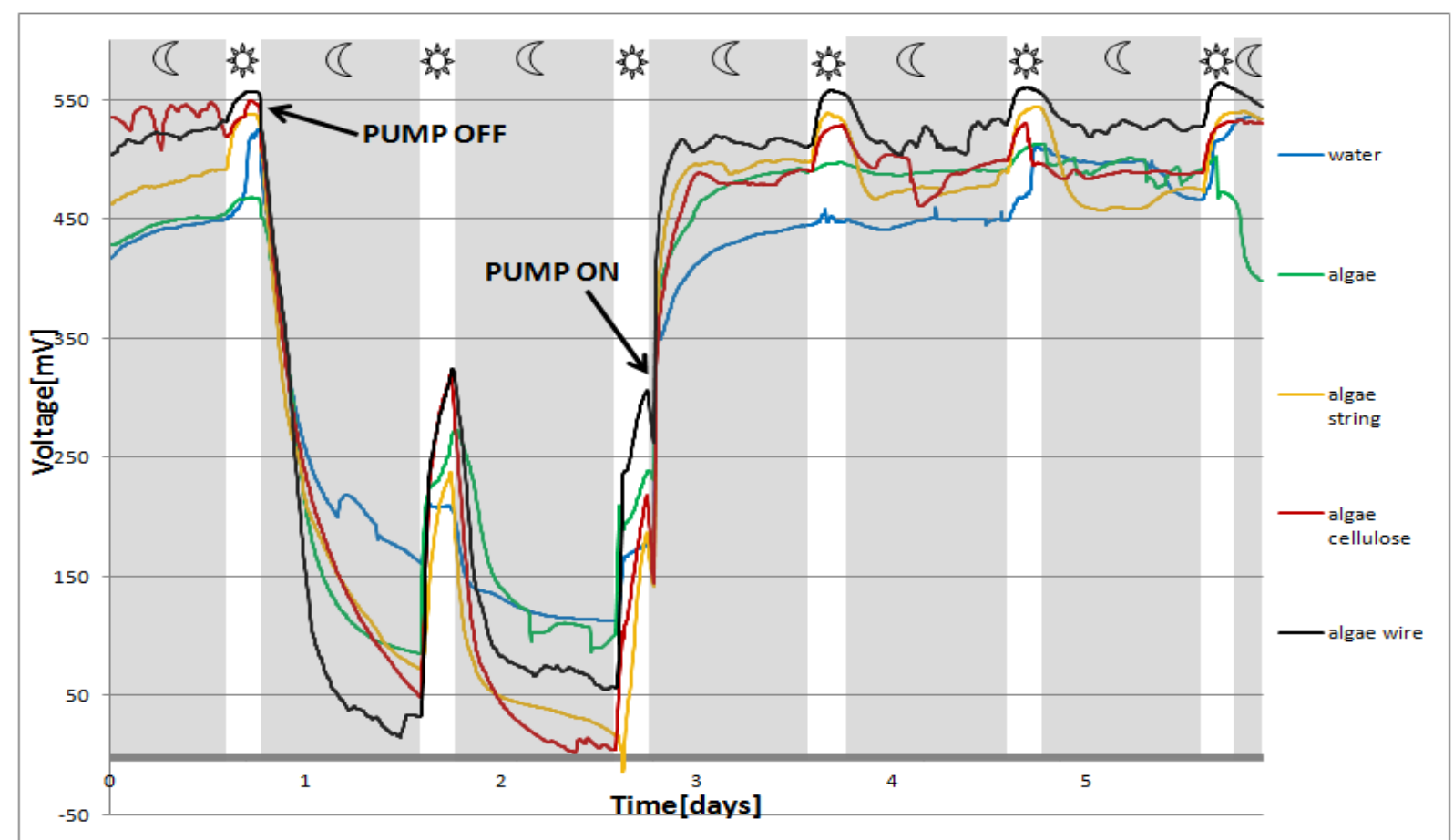

Figure 3. Open circuit voltage (OCV) values of photosynthetic cathode MFCs. 4h day/20night cycle.

Despite the fact that photosynthesis stops inside both the MFC cathode and photoreactor flasks, the amount of oxygen concentration pooled inside the bioreactor compensates for the lack of oxygen production during the dark period inside the smaller MFC cathode chamber. This is the algal lagoon hysteresis effect, which allows the photoreactor to function as an oxygen reservoir, and depending on the hydraulic retention time, to maintain a stable supply of oxygen to the target cathode half-cell. Furthermore, the fact that the level of OCV when the pump is switched ON is identical to the voltage level when operating in batch mode under light conditions (Fig 2) may suggest that the output is a function of oxygen.

Previous work reported on an algal growth unit as well as the spontaneous colonisation of the initially abiotic cathode by photosynthetic biofilm [9]. A similar study reported biomass being used as the substrate for anaerobic digestion in a closed loop reactor, and found the algal culture can deliver the necessary electron acceptors for the cathode without mechanical 
aeration [10]. Microscopic examination revealed cells of cyanobacteria and photosynthetic eukaryotes as well as heterotrophic bacteria and protozoa, thus presenting a balanced phototrophic MFC ecosystem. This synergistic interaction between photosynthetic organisms and heterotrophs exists in natural aquatic environments [19] and is used in wastewater treatment lagoons [11], as well as in sediment-type MFCs [20]. This interaction is monitored in the present study, by the use of MFC in open circuit conditions suggesting its practical use as an environmental sensor.

\subsection{Practical implementation}

The MFCs operated in the current study require external pumping, which will impact the energy balance of a system operating remotely. In the context of self-sustainable systems operating off-the-grid, it was attempted to demonstrate that this pumping can be energised by the MFC stack itself. A dc impeller pump was powered continuously by the energy produced from these same MFCs (15 already described +1 for balanced configuration). The energising of the pump was performed via a 5F super-capacitor (Fig. 5), when the MFC stack was connected in a series/parallel configuration. Under this condition, 2 MFC units were connected in parallel, and the resulting 8 pairs, were connected in series. The light/dark cycle was set again at $14 \mathrm{~h}$ day $/ 10 \mathrm{~h}$ night. The super-capacitor was charged to the stack's maximum voltage $3.09 \mathrm{~V}$ for this configuration for $24 \mathrm{~h}$, which allowed the operation of the impeller pump for 67 secs until the capacitor voltage decreased to $1.0 \mathrm{~V}$, at which point the pump stopped. Charging of the capacitor was repeated for a second time, and the voltage reached $3.04 \mathrm{~V}$, which took $25 \mathrm{~h}$ and allowed the pump to run for 61 secs, whereas the third time, the capacitor voltage reached $2.88 \mathrm{~V}$ in $23 \mathrm{~h}$, which operated the pump for 49 secs. The diminishing power output was probably due to anodic feedstock depletion, since the MFC anodes were not fed during the time of the test. It may be observed, that the voltage charging rate seemed to stabilise during the dark phase, and significantly increase after the light was turned ON. The 
impact of illumination becomes apparent, which emphasises the importance of exposure to solar radiation for real MFC systems.

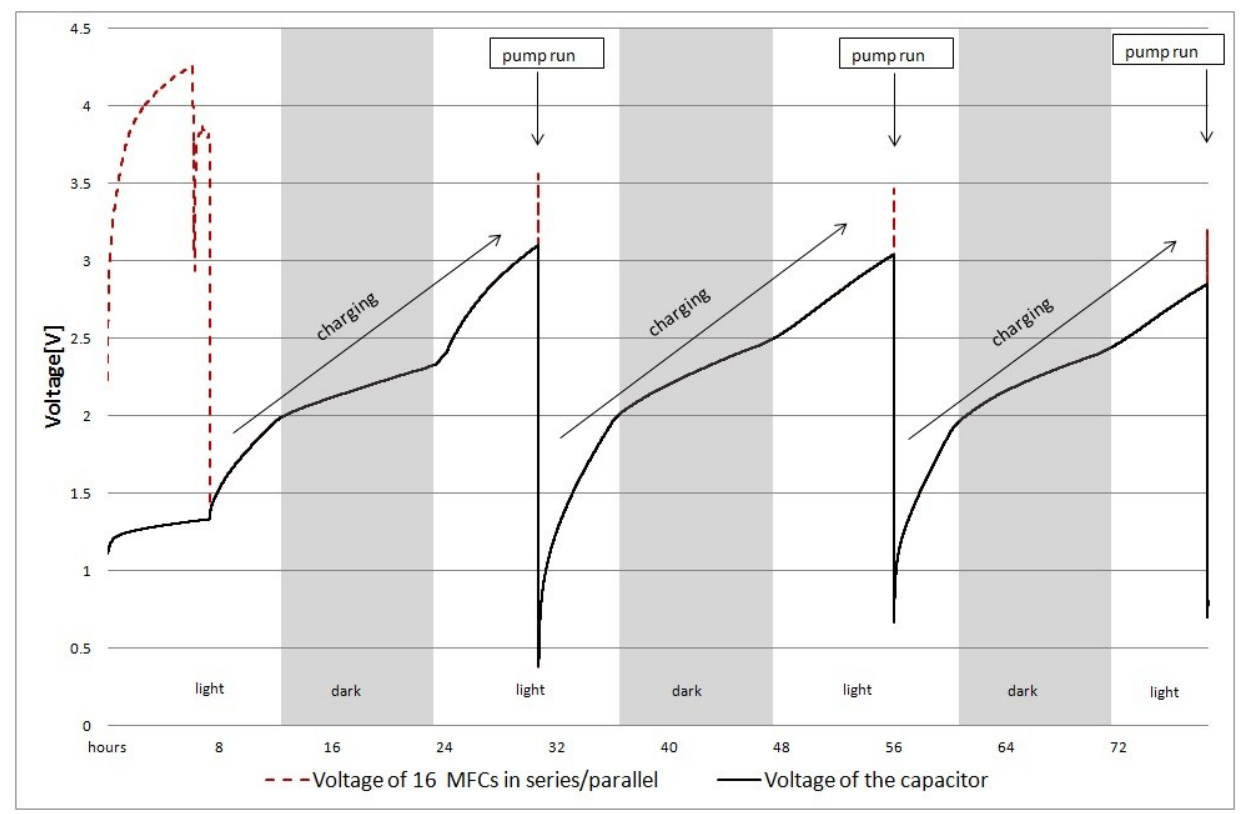

Figure4. Charging of a $5 F$ super-capacitor to run an impeller pump in $\sim 24$ h intervals.

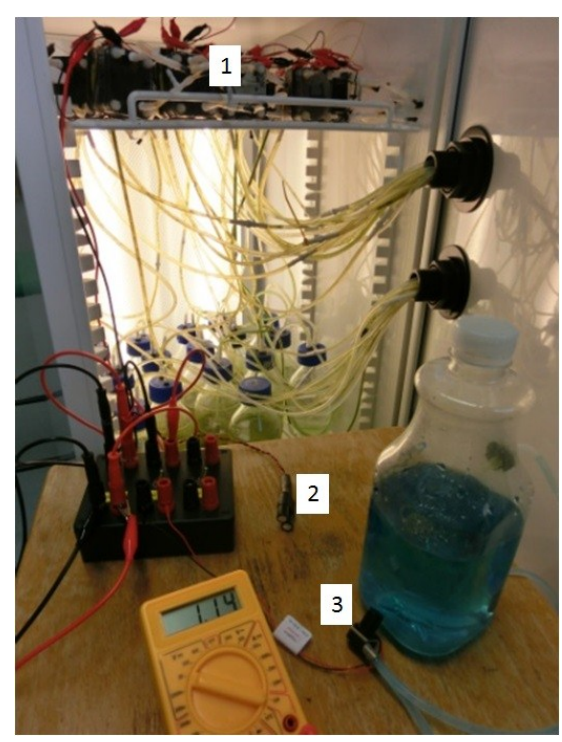

Figure5. Demonstration of the practical implementation of the 16 MFC stack connected in a series/parallel configuration (1-MFCs, 2-supercapacitor, 3-impeller pump).

\section{Discussion}

The feasibility of photosynthetic cathodes, to facilitate the ORR and provide a means of electrical energy and biomass recovery, has been demonstrated in MFC systems. The mixed algal cultures did not require maintenance, carbon source, $\mathrm{CO}_{2}$ addition, $\mathrm{pH}$ control or growth 
media whereas in previous studies, high maintenance, addition of $\mathrm{CO}_{2}[21,22]$ to improve cathode stability [23], was necessary to maintain the algal growth, however this is energy intensive. A similar concept of a photo cathode with Chlorella vulgaris has been demonstrated in MFCs [21] and in Microbial desalination cells [23] however, the laboratory set-ups require strictly controlled environments with thermal sterilisation for the monoculture maintenance. In the present study, even though the photoreactors were not kept sterile, the algal community became dominant in the cathode as has shown to be the case in sediment MFCs [20]. The advantage of mixed cultures of photosynthetic organisms and heterotrophic bacteria demonstrated the characteristics of natural ecosystems, which do not require the manual addition of $\mathrm{CO}_{2}$. Moreover, the photosynthetic activity of the dominant microalgae prevented the sub-dominant heterotrophs to consume the oxygen completely.

The tested configuration successfully produced algal biomass, which has been previously shown to serve as a suitable anodic feedstock for the MFC system [17, 27]. The possibility of biomass recovery was previously reported by Microbial Carbon Capture Cells (MCCs), where sequestration of carbon dioxide discharged from the anode was piped through the cathodic solution containing Chlorella vulgaris [26]. Also, a self sustained sediment type of MFC was explored for producing electricity without the external carbon input; however due to its membrane-less design, dissolved oxygen produced by photosynthetic organisms, had inhibitory effects on the anode current production [20]. Here, the positive light effect was actually improving the performance of the MFC stack to power a real world application.

The algal growth provided dissolved oxygen to the cathode reaction of the MFC with two different bioenergy products: bioelectricity from the MFCs, and algal biomass production for use as a substrate. Further optimisation of the MFC configuration is still required to maximise the efficiency of the MFCs [25] and this will be the subject of further study. 
Production of advanced biofuels is very energy expensive and technologically complicated therefore, the integration of photosynthesis in the MFC cathode appears to be particularly attractive. This nutrient reclamation from waste through the photosynthetic activity of microalgae had already been recognised as having a great potential in the 1950s [12], and has been used in High Rate Algal Ponds [29]. The use of living organisms to reduce the anthropocentric impact on the environment has been a subject of environmental biotechnology. The biological reactions occurring in the algal ponds reduce the organic content of the wastewater by bacterial decomposition, and convert them through photosynthesis into algal biomass.

The benefits of algal species in wastewater treatment include high growth rate when fed with predominantly nitrogen and phosphorous rich wastewater effluents, which allows the formation of aggregates for simpler harvest. If these nutrients are supplied in the MFC, then through the membrane selective transport, cations can be supplied for algal growth. There still are many technical and economic obstacles to overcome before practical implementation is realised [30]. Therefore, the most important and economically viable integration of biomass recovery via photosynthesis [31] has been explored in an exemplar practical application as a viable demonstration of the self-sustainability potential.

\section{Conclusions}

This study presents the sustainable oxygenation of the MFC cathode by photosynthetic biocatalysts in a 'lagoon' type scenario. This is the first time that the stack of completely biotic MFCs incorporating photosynthetic organisms in the cathode has been shown to power a practical application such as the impeller pump. Furthermore, it is allowing a route for energy abstraction from the biomass grown in the photo-assisted MFCs. The development of MFC-based technologies could help utilise locked-in waste products for energy production in a carbon-neutral manner. A presented design of the phototrophic MFC systems will make it 
possible to convert solar energy into biomass and electricity and possibly power the remote sensing systems for monitoring environmental conditions.

\section{Acknowledgements}

This work is funded by the Engineering and Physical Sciences Research Council (EPSRC)

UK grant numbers EP/I004653/1 and EP/L002132/1. The authors would like to thank Dr Man-Kim Cheung for his valuable help and expertise in algal culturing.

\section{References}

[1] W. Habermann, E. Pommer, Biological fuel cells with sulphide storage capacity, Appl. Microbiol. Biotechnol. 35 (1991) 128-133.

[2] B.H. Kim, I.S. Chang, G.C. Gil, H.S. Park, H.J. Kim, Novel BOD (biological oxygen demand) sensor using mediator-less microbial fuel cell, Biotechnol. Lett. 25 (2003) 541 545.

[3] I. Ieropoulos, C. Melhuish, J. Greenman, I. Horsfield . EcoBot-III: a robot with guts. In: Fellermann H, Dorr M, Hanczyc M, Laursen LL, Maurer S, Merkle D, et al., editors. Proceedings of the Alife XII Conference; 2010 Aug 19-23; Odense, Denmark. London: MIT Press; 2010. p. 733-740.

[4] I.A. Ieropoulos, P. Ledezma, A. Stinchcombe, G. Papaharalabos, C. Melhuish, J. Greenman, Waste to real energy: the first MFC powered mobile phone, Physical Chemistry Chemical Physics. 15 (2013) 15312-15316.

[5] M. Rosenbaum, Z. He, L.T. Angenent, Light energy to bioelectricity: photosynthetic microbial fuel cells, Curr. Opin. Biotechnol. 21 (2010) 259-264.

[6] D.P. Strik, H.V. Hamelers, C.J. Buisman, Solar energy powered microbial fuel cell with a reversible bioelectrode, Environ. Sci. Technol. 44 (2009) 532-537.

[7] X. Wu, T. Song, X. Zhu, P. Wei, C.C. Zhou, Construction and Operation of Microbial Fuel Cell with Chlorella vulgaris Biocathode for Electricity Generation, Appl. Biochem. Biotechnol. 171 (2013) 2082-2092.

[8] X.A. Walter, J. Greenman, I.A. Ieropoulos, Oxygenic phototrophic biofilms for improved cathode performance in microbial fuel cells, Algal Research. 2 (2013) 183-187.

[9] I. Gajda, J. Greenman, C. Melhuish, I. Ieropoulos, Photosynthetic cathodes for Microbial Fuel Cells, Int J Hydrogen Energy. 38 (2013) 11559-11564.

[10] L. De Schamphelaire, W. Verstraete, Revival of the biological sunlight-to-biogas energy conversion system, Biotechnol. Bioeng. 103 (2009) 296-304.

[11] W.J. Oswald, H. Gotaas, H.F. Ludwig, V. Lynch, Algae symbiosis in oxidation ponds: III. Photosynthetic oxygenation, Sewage and Industrial Wastes. 25 (1953) 692-705.

[12] W.J. Oswald, H.B. Gotaas, Photosynthesis in sewage treatment, Trans.Am.Soc.Civ.Eng. 122 (1957) 73-105.

[13] J.P. Hoffmann, Wastewater treatment with suspended and nonsuspended algae, J. Phycol. 34 (1998) 757-763.

[14] R.A. Rozendal, H.V. Hamelers, C.J. Buisman, Effects of membrane cation transport on pH and microbial fuel cell performance, Environ. Sci. Technol. 40 (2006) 5206-5211. 
[15] P. Kuntke, K. Śmiech, H. Bruning, G. Zeeman, M. Saakes, T. Sleutels, H. Hamelers, C. Buisman, Ammonium recovery and energy production from urine by a microbial fuel cell, Water Res. 46 (2012) 2627-2636.

[16] L. Xiao, E.B. Young, J.A. Berges, Z. He, Integrated photo-bioelectrochemical system for contaminants removal and bioenergy production, Environ. Sci. Technol. 46 (2012) $11459-11466$.

[17] S.B. Velasquez-Orta, T.P. Curtis, B.E. Logan, Energy from algae using microbial fuel cells, Biotechnol. Bioeng. 103 (2009) 1068-1076.

[18] N. Rashid, Y. Cui, S.U.R. Muhammad, J. Han, Enhanced electricity generation by using algae biomass and activated sludge in microbial fuel cell, Sci. Total Environ. 456 (2013) 91-94.

[19] J.J. Cole, Interactions between bacteria and algae in aquatic ecosystems, Annu. Rev. Ecol. Syst. (1982) 291-314.

[20] Z. He, J. Kan, F. Mansfeld, L.T. Angenent, K.H. Nealson, Self-sustained phototrophic microbial fuel cells based on the synergistic cooperation between photosynthetic microorganisms and heterotrophic bacteria, Environ. Sci. Technol. 43 (2009) 1648-1654.

[21] E.E. Powell, M.L. Mapiour, R.W. Evitts, G.A. Hill, Growth kinetics of Chlorella vulgaris and its use as a cathodic half cell, Bioresour. Technol. 100 (2009) 269-274.

[22] J. Lobato, A. González del Campo, F.J. Fernández, P. Cañizares, M.A. Rodrigo, Lagooning microbial fuel cells: A first approach by coupling electricity-producing microorganisms and algae, Appl. Energy. 110 (2013) 220-226.

[23] J.J. Fornero, M. Rosenbaum, M.A. Cotta, L.T. Angenent, Carbon dioxide addition to microbial fuel cell cathodes maintains sustainable catholyte $\mathrm{pH}$ and improves anolyte $\mathrm{pH}$, alkalinity, and conductivity, Environ. Sci. Technol. 44 (2010) 2728-2734.

[24] B. Kokabian, V.G. Gude, Photosynthetic microbial desalination cells (PMDCs) for clean energy, water and biomass production, Environmental Science: Processes \& Impacts. 15 (2013) 2178-2185.

[25] G. Sun, A. Thygesen, M.T. Ale, M. Mensah, F.W. Poulsen, A.S. Meyer, The significance of the initiation process parameters and reactor design for maximizing the efficiency of microbial fuel cells, Appl. Microbiol. Biotechnol. (2014) 1-13.

[26] X. Wang, Y. Feng, J. Liu, H. Lee, C. Li, N. Li, N. Ren, Sequestration of CO2 discharged from anode by algal cathode in microbial carbon capture cells (MCCs), Biosensors and Bioelectronics. 25 (2010) 2639-2643.

[27] A. Lakaniemi, O.H. Tuovinen, J.A. Puhakka, Production of electricity and butanol from microalgal biomass in microbial fuel cells, BioEnergy Research. 5 (2012) 481-491.

[28] G. Buelna, K. Bhattarai, J. De la Noue, E. Taiganides, Evaluation of various flocculants for the recovery of algal biomass grown on pig-waste, Biological wastes. 31 (1990) 211-222.

[29] R. Craggs, S. Heubeck, T. Lundquist, J. Benemann, Algal biofuels from wastewater treatment high rate algal ponds. Water Science \& Technology. 63 (2011).

[30] A.E. Franks, K. Nevin, Microbial fuel cells, a current review, Energies. 3 (2010) 899919.

[31] V. Gude, B. Kokabian, V. Gadhamshetty, Beneficial bioelectrochemical systems for energy, water, and biomass production, J Microb Biochem Technol. 6 (2013) 2. 